\title{
Design of a SolidWorks-based Vegetable Tray Seeder
}

\author{
GUO Yia ${ }^{a}$ LIU Jiwei ${ }^{b}$ \\ Department of Horticulture, Beijing Vocational College of Agriculture, Beijing, 102442, China \\ aemail: guoyibvca@163.com, bemail: 131900208@163.com
}

\section{Keywords: Vegetable, Tray Seeder, SolidWorks, Design}

\begin{abstract}
In order to realize seeding mechanization in vegetable tray seedling, a SolidWorks-based vegetable tray seeder, consisting of the workbench, seeding device, dynamic system and control system, is designed. The experimental structure of a test unit based on this design shows that the machine is able to automatically suck and release seeds. The seed suction device works stably with an excellent control system, taking 12 seconds to do seed sowing in one tray in uniformity. With less than $5 \%$ of missed holes and less than $2 \%$ of repeated holes, the seeder is able to meet the requirements for seeding of various leaf vegetables such as lettuce and rape. Characterized by a simple structure, low cost of manufacturing, easy operation, safety, and reliability, this seeder can effectively increase the efficiency of vegetable tray seeding, lower labor intensity and save quantity of seeds used. It is easy to promote and apply the seeder in vegetable production.
\end{abstract}

\section{Introduction}

In order to increase the efficiency of vegetable production, tray seedling is often applied in modern vegetable production. The tray seeding devices used at present generally have complicated structures with huge investment and large coverage. Therefore, most of vegetable producers adopt manual seeding for tray seedling with low work efficiency but high labor intensity. Especially for the small-sized vegetable seeds which weigh less than 2 kilograms every thousand, there is a problem of great waste.

Over the past few years, the computer-aid design (CAD) has become an indispensable tool in mechanical design industry. Characterized by powerful functions, easiness of learning and application and technical innovation, SolidWorks has become one of the mainstream 3D CAD solutions, effectively reducing errors during design as well as improving the product quality so as to achieve higher efficiency of mechanical design. Based on SolidWorks, Dai Yizheng, et al. designed the pneumatic centralized divider [1]; Li Fei, et al. designed the 3D suspended garage device [2]; Liu Zhigang, et al. designed the structure of the pepper picker [3]; Yang Yuefeng, et al. designed the automatic coin segregator [4]; Xuan Guantao, et al. designed the small-sized precision vegetable tray seeder [5]; Pan Shiqiang, et al. designed the corn stalk bander [6]; Wang Jingli, et al. designed the optimized dual-disc earth covering device [7]; Guo Xiaohuan, et al. designed the scrapped film pick-up bander [8]; Guo Yi, et al. designed the layer-type aeroponics device [9] as well as the 3D sprout cultivation device [10].

For the purpose of meeting the requirements of vegetable tray seedling for seeding mechanization, a SolidWorks-based vegetable tray seeder is designed and described in this article. Characterized by a simple structure, low cost of manufacturing, easy operation, safety and reliability, this seeder is capable of effectively increasing work efficiency of the vegetable tray seeding, lowering labor intensity, saving the quantity of seeds used and achieving excellent seeding quality. Thus, it is easy to promote and apply the seeder in vegetable production. 


\section{General Design Proposal}

The vegetable tray seeder consists of workbench, seeding device, dynamic system, control system, etc. (See Fig.1). The workbench is designed to install all parts; the seeding device adopts air suction to enable the air pump to work on the seed suction device so as to suck and release seeds; the dynamic system adopts the linear motor to drive the seed suction device in reciprocating motion; the control system adopts the SCM system for the purpose of controlling the automation of the seeding device and the dynamic system.

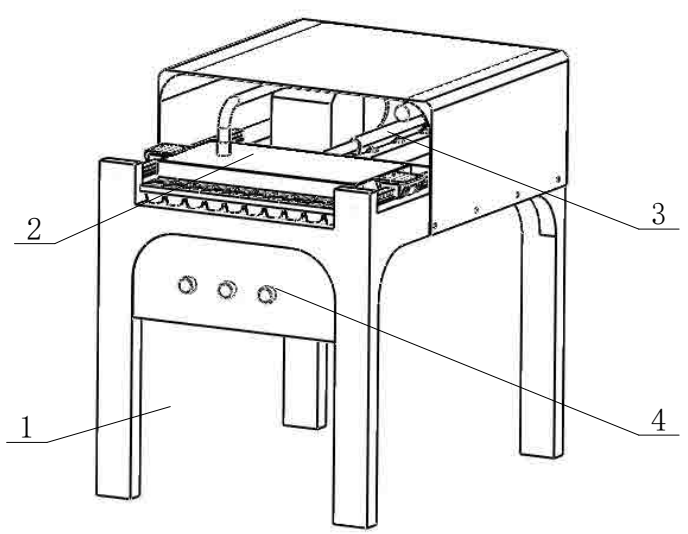

Fig.1 General structure

1-workbench 2-seeding device 3-dynamic system 4-control system

When the vegetable tray seeder works, first press the on-button to enable the seeder to work, and then put the tray where seeding is about to start on the correct spot of the workbench; when the sensor receives the signal put inside the tray, send the signal back to the master chip; open the valve designed for controlling air suction to enable the seed suction device to suck seeds from the seed box; then start the linear motor to push the seed suction device above the tray and close the air suction valve; the seeds fall inside the tray under the action of gravity; then, the linear motor takes the seed suction device back to the upper part of the seed box; manually take out the trays with seeds sowed so as to complete the seeding of one tray. If continued seeding is required, simply place the tray inside again. After completion of seeding of all trays, press off-button to end the operation of the seeder.

\section{Structure Design}

Workbench Design. The workbench consists of the column, bench top, guide rail, sliding block and hood (see Fig.2). For manual convenience, the sitting position and withdrawable tray are adopted. According to the principles of ergonomics, the height of the workbench is designed to be $800 \mathrm{~mm}$. The column is used to support the top. The middle of the bench top is used to hold the seed box and the tray. Both sides of the bench top are installed with the guide rail and sliding block. The hood is bolted to the bench top, to protect movement parts and prevent personal injuries. The workbench is used to install parts including the seeding device, dynamic system and control system. 


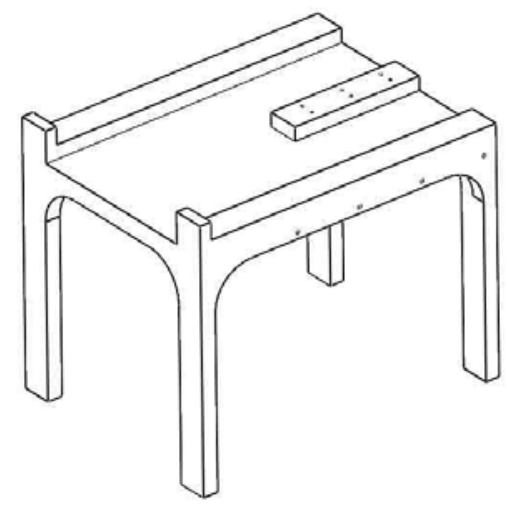

Fig.2 Workbench

Design of Dynamic System. In order to simplify the structure of the seeder, the dynamic system adopts the linear motor. In order to meet the requirements of work, choose LX600 linear motor with DC12V as working voltage, $300 \mathrm{~mm}$ as stroke and $50 \mathrm{~mm} / \mathrm{s}$ as speed. The seeding rate of each tray is accordingly determined to be $12 \mathrm{~S}$.

Design of the Seeding Device. The seeding device consists of seed suction device, seed box, air pump, valve, and air duct (Fig.3). The seed suction device is designed to suck and release seeds, including shell and seed suction plate. The shell is constructed as a sealed box. The seed suction plate is connected to the bottom of the shell with bolts. In order to meet the requirements of seeding for various diameters of seeds and different sizes of trays, there are varied types of seed suction plates designed. We can meet the requirements of seeding for different diameters of seeds and varied sizes of trays through replacing seed suction plates. The seeding device is bolted to the sliding block. Driven $b$ the linear electric motor, the seed suction device and the sliding block make reciprocating motion on the guide rail. Seed box is constructed for the purpose of storing the seeds to be sowed. The air pump sucks air from the seed suction device through the air duct so as to suck seeds from the seed box. A valve is available in the middle part of the air duct. The valve is controlled by the control system. When the valve is opened, it sucks seeds. When the valve is closed, it releases seeds.

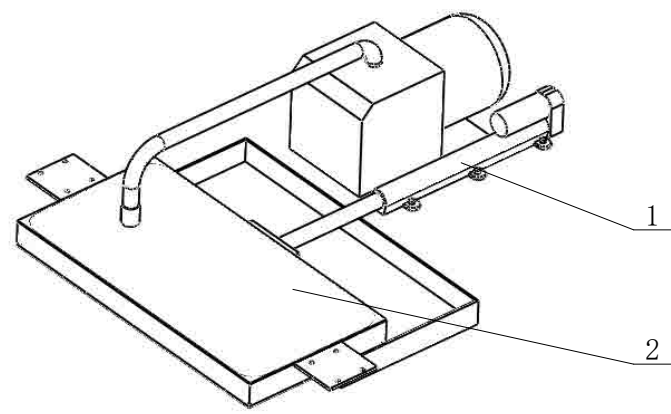

Fig.3 Dynamic system and seeding device 1-dynamic system 2-seeding device

Design of the Control System. The control system adopts the SCM system, consisting of SCM system, relay, sensor, and switch button. The sensor is installed to the place where the tray of the workbench is put to sense the signal put inside the tray and send the signal back to the master chip. The master chip controls, via programs, connection and disconnection of the relay of air pump and the relay of linear motor so as to suck seeds, displace the seed suction device and release seeds. The switch button is used to control starting and shutting of the seeder.

Simulation Analysis. Based on the result of the structure design, the designed parts are assembled with SolidWorks through its assembling function. Interference check and motion simulation analysis are also conducted. After the result of design is tested and approved, 2D engineering drawings of 
parts and assemblies are made with SolidWorks through its function of engineering graphics for the manufacturer to make the seeder.

\section{Conclusions}

The vegetable tray seeder based on this design is tested at the agricultural technology demonstration park of Beijing Vocational College of Agriculture. The result of the test shows that the seeder is capable of automatically sucking and releasing seeds. The seed suction device works stably with excellent control system at rate of 12 seconds for seeding for every tray with uniformity and less than $5 \%$ of missed holes for seeding and less than $5 \%$ of repeated holes so as to meet the requirements of seeding for different leaf vegetables such as lettuce and rape. The seeder is characterized by a simple structure, low cost of manufacturing, easy operation, safety, reliability, high work efficiency, etc. It is easy to promote and apply the seeder in vegetable production.

\section{Acknowledgements}

This article is funded by the Cultivation Technology Research and Demonstration on Special Leaf Vegetables like Ice Plants Project (Project No.: XY-YF-17-01) of Technology Development and Demonstration and Promotion Fund of Beijing Vocational College of Agriculture).

\section{References}

[1] DAI Yizheng, LUO Xiwen, WANG Zaiman, ZENG Shan, ZANG Ying, YANG Wenwu, ZHANG Minghua, WANG Baolong, XING He. Design and experiment of rice pneumatic centralized seed distributor [J]. Transactions of the Chinese Society of Agricultural Engineering (Transactions of the CSAE), 2016, 32 (24): 36-42.

[2] LI Fei, YANG Guotai, SUN Guangxing. Design of the Suspension Device of Stereoscopic Car-based based on SolidWorks [J]. Journal of Jinggangshan University (Natural Science), 2017, 38(01): $73-77$.

[3] LIU Zhigang, ZHAO Xiaoyan. Structure Design and Motion Simulation of High Branch Pepper Picking Device Based on SolidWorks [J]. Machine Building \& Automation, 2017, 46 (02): 130-132. [4] YANG Yuefeng, ZHANG Xiaokai, YANG Tiankuo, SHI Xuanyu, LI Yuandong, SUN Jianan. Innovative Mechanical Structure Design of Automatic Coin Separator Based on SolidWorks [J]. Mechanical Engineer, 2017, (02): 98-99.

[5] XUAN Guantao, SHAO Yuanyuan, HOU Jialin, WANG Lianwen, LV Zhaoqin. Design and Test of Small Vegetable Plug Tray Precision Seeder [J]. Journal of Agricultural Mechanization Research, 2018, 40 (02): 85-89.

[6] PAN Shiqiang, CAO Zifu, ZHAO Wanning, YANG Yulin. Design on corn straw bundling machine based on SolidWorks [J]. Journal of Chinese Agricultural Mechanization, 2016, 37 (6): 31-34.

[7] Wang Jingli, Liu Xuanwei, Han Mingyue, Hou Haidong, Liu Fangjun. Optimization design of double-disc coverer [J]. Journal of Chinese Agricultural Mechanization, 2016, 37 (1): 37-39.

[8] GUO Xiaohuan, DAI Fei, ZHAO Wuyun, SHI Linrong, SHUAI Zhongkui, WU Yifei. Design of the whole double furrow film-picking baler machine $[\mathrm{J}]$. The Journal of Chinese Agricultural Mechanization, 2016, 37 (9): 32-36, 55.

[9] GUO Yi, CHEN Lanfen, ZHANG Guiqin. Design of a Sprout Layer-rack Aeroponic Cultivation Device [A]. Proceedings of 2016 7th International Conference on Mechatronics, Control and Materials (ICMCM 2016) [C]. 2016: 6.

[10] GUO Yi, ZHANG Guiqin. Development of A Design System for the Sprout Vertical Cultivation Device [A]. Proceedings of 2015 3rd International Conference on Mechanical Engineering and Intelligent Systems (ICMEIS 2015) [C]. 2015: 6. 